\title{
O que se aprende e se ensina no processo de mútua formação de professores de Salas de Leitura?
}

\section{What is learned and what is taught in the process of mutual education of reading room teachers?}

https://doi.org/10.34112/2317-0972a2020v38n78p99-113

\section{Cláudia Beatriz de Castro Nascimento Ometto ${ }^{1}$ Renata Cristina Oliveira Barrichelo Cunha}

Resumo: O artigo analisa o processo de formação de um grupo de professores de Salas de Leitura da rede estadual paulista no contexto de um projeto de pesquisa que articula a universidade pública e uma Diretoria Regional de Ensino. A pergunta orientadora da pesquisa é: como os professores se apropriam das experiências de formação e (re)organizam suas concepções e práticas nas Salas de Leitura? Parte-se do pressuposto de que o desenvolvimento profissional docente ocorre por meio da socialização das teorias práticas dos professores e da problematização de seu próprio conhecimento e o dos outros. $\mathrm{O}$ material analisado é composto por seis entrevistas com professoras e os resultados da pesquisa evidenciam que pela interação e interlocução nas atividades de formação de e para leitura os professores aproximaram-se de outros olhares não só para as práticas pedagógicas vividas, mas também para os modos de se relacionarem com os colegas no cotidiano escolar, a favor da leitura. PALAVRAS-ChAVE: Formação de professores; Sala de Leitura; práticas de leitura.

ABSTRACT: The article analyses the educational process of a group of reading room teachers of a public Brazilian school, in the Sao Paulo state, in the context of a research project in public university and a regional educational board of directors. The guideline

1. Universidade Estadual de Campinas, Campinas, SP, Brasil.

2. Centro Universitário Salesiano de São Paulo, Americana, SP, Brasil. 
O que se aprende e se ensina no processo de mútua formação de professores de...

question of the research is: How do the teachers appropriate the educational experiences and (re)organize their own conceptions and practices in reading room classes? The study starts from the assumption that the teachers' professional development happens through socialization of their practices and by understanding the problematic issues of their own knowledge as well as the students. The material comprises six interviews with teachers and the outcome of the research highlights that by interaction and interlocution in the formation and reading activities, the teachers approached other ways of looking to the pedagogical practices experienced, and also in the kind of relationships with the school colleagues, in behalf of reading.

KEYWORDS: Teachers education; Reading Room; reading practices.

\section{INTRODUÇÃO}

Este artigo analisa o processo de formação de um grupo de professores responsáveis pelas Salas de Leitura da rede estadual paulista que participam de um projeto de pesquisa ${ }^{3}$ interessado em aspectos relativos à formação de leitores na escola básica e às práticas de leitura possibilitadas pelos professores aos alunos do Ensino Fundamental - anos finais.

O foco da discussão do texto está na teorização dos pressupostos da formação desenvolvida em parceria com os pesquisadores e na resposta à seguinte questão: como os professores se apropriam das experiências de formação e (re)organizam suas concepções e práticas nas Salas de Leitura?

As Salas de Leitura são espaços escolares instaurados pela Resolução SE 15/2009 (SÃO PAULO, 2009). Segundo a Resolução, a finalidade principal da Sala de Leitura é oferecer aos alunos de todos os cursos e modalidades de ensino "oportunidade de acesso a livros, revistas, jornais, folhetos, catálogos, vídeos, DVDs, CDs e outros recursos complementares, quando houver" (p. 39). No que diz respeito à formação inicial desses professores, a Resolução SE 70/2011 (SÃO PAULO, 2011) determina que o requisito é ser portador de diploma de licenciatura plena, sem exigência de formação em Letras.

A Secretaria de Educação do estado de São Paulo (SEESP) realiza a formação de seus profissionais via Escola de Formação e Aperfeiçoamento dos

3. O projeto de pesquisa "O trabalho com leitura no ensino fundamental - anos finais: das contribuições de um grupo de pesquisa à formação de professores mediadores de leitura às relações de ensino em salas de leitura escolares" é financiado pelo Edital Universal - CNPq 2017-2020 (Processo no 401404/2016-1). 
Professores (EFAP), criada em $2009^{4}$, e oferece cursos geralmente na modalidade à distância, além de abrir possibilidades como a parceria com outras instituições e com as Diretorias de Ensino (DE) em cursos que podem ter o formato presencial ou semipresencial. No caso da formação para professores de Salas de Leitura há uma parceria entre a SEESP, por meio do Centro de Referência em Educação (CRE) Mário Covas e Coordenadoria de Estudos e Normas Pedagógicas (CENP), com o Instituto Ayrton Senna (IAS) ${ }^{5}$, por meio do Programa SuperAção Jovem ${ }^{6}$.

A Diretoria de Ensino da Região de Piracicaba, lócus dessa pesquisa, não aderiu ao programa proposto pela SEESP, optando por uma parceria com a Universidade Pública, a fim de construir um percurso de formação contínua de longa duração. Essa parceria ocorre desde 2014 e a partir de 2017 passou a contar com financiamento do Conselho Nacional de Desenvolvimento Científico e Tecnológico - CNPq.

\section{FORMAÇÃO DOCENTE E SOCIALIZAÇÃO DAS REFLEXÕES E TEORIAS PRÁTICAS DOS PROFESSORES}

Partimos do princípio de que a formação como um processo subjetivo "inclui as trajetórias de vida, os referentes culturais e os valores sociais em um amálgama de possibilidades de construção da profissionalidade docente, sendo entendida como a profissão em ação” (CUNHA, 2013, p. 11).

A prática profissional, a partir dessa concepção, não é compreendida como simples aplicação instrumental de uma técnica ou de uma teoria, uma vez que as questões educacionais e as ações práticas não podem ser controladas e previstas de acordo com padrões e modelos rígidos. De acordo com Tardif (2000), a prática do professor é um processo de filtração dos conteúdos da formação em função das características e exigências do trabalho. Isso significa que os professores são portadores de saberes profissionais (ou saberes de ação ou saberes de trabalho) que são mobilizados e construídos no contexto da ação. A formação teórica (conhecimentos universitários), na

4. Para maiores informações, sugerimos acessar a página oficial disponível em http://www.escoladeformacao. sp.gov.br/portais/Default.aspx?tabid=6257. Acesso em: 13 de dezembro de 2018.

5. Para maiores informações, sugerimos acessar a página oficial disponível em https://institutoayrtonsenna. org.br/pt-br.html. Acesso em: 20 de dezembro de 2018.

6. Para maiores informações, sugerimos acessar a página oficial disponível em https://institutoayrtonsenna. org.br/content/institutoayrtonsenna/pt-br/radar/Parceria_com_Secretaria_de_Educao_de_SP_ qualifica_professores.html. Acesso em: 20 de dezembro de 2018. 
O que se aprende e se ensina no processo de mútua formação de professores de...

relação com os saberes profissionais, oferece elementos que ampliam o repertório e ajudam os professores a compreenderem melhor seu trabalho.

Para Cunha (2013, p. 13), a valorização da epistemologia da prática não deve ser confundida com opraticismo inconsequente. A autora argumenta a favor da teorização articulada com a prática e com o cotidiano dos docentes e alunos.

O que questionamos nos processos de formação, com base em Cochran-Smith e Lytle (1999) e Zeichner (1998), é a imagem de um conhecimento para o uso e a de professores como executores que precisam exclusivamente implementar, traduzir ou colocar em prática o que adquirem com os especialistas fora da sala de aula. Não assumimos, portanto, a posição de pesquisadores que fornecem diagnósticos e soluções para os problemas das práticas dos professores, pois consideramos a educação como um processo complexo e a atividade educativa suscetível às circunstâncias (DINIZ-PEREIRA, 2011).

Tardif (2000, p. 19) destaca que o desafio dos formadores e pesquisadores é organizar a dinâmica formativa segundo uma "lógica profissional centrada no estudo das tarefas e realidades do trabalho dos professores".

Nessa perspectiva de formação, tanto a produção de conhecimento quanto seu uso são considerados inerentemente problemáticos e estão sempre abertos a discussão. Cochran-Smith e Lytle (2009) reforçam, na mesma perspectiva de Zeichner (1998) e Tardif (2000), que a prática educacional não é simplesmente instrumental, no sentido de descobrir como conseguir que as coisas sejam feitas, mas destacam a importância dos aspectos sociais e políticos do ensino, ou seja, compreender quem decide o que deve ser feito, por que algo deve ser feito e quais interesses atendem. Essa perspectiva se coaduna com as referências histórico-culturais, uma vez que é no âmbito social que estão a cultura, as relações políticas, sociais, econômicas, o tipo de estrutura social, as ideologias dominantes e as relações implícitas e explícitas da educação.

A produção de conhecimento, nesse caso, é entendida como um ato pedagógico - construído coletivamente no contexto da ação, a partir de situações problemáticas, um processo de teorização que se dá sempre e necessariamente na e pela linguagem. Nesse sentido, o conhecimento profissional está orientado para reorganizar os enfoques conceituais e interpretativos que os professores usam para refletir e teorizar sobre a prática e relacionar seus esforços a questões políticas, intelectuais e sociais mais amplas, bem como ao trabalho de outros pesquisadores, professores e comunidades (COCHRAN-SMITH e LYTLE, 1999). 
Diferentemente da concepção de conhecimento para a prática (conhecimento para o uso), a concepção de conhecimento da prática não distingue conhecimento formal (produzido segundo as convenções da pesquisa educacional) e prático (produzido na atividade de ensino) e não divide professores especialistas, de um lado, e aqueles menos competentes ou novatos, de outro.

De acordo com Cochran-Smith e Lytle (1999), o pressuposto da concepção de conhecimento da prática é que, estudando colaborativamente, os professores produzem um conhecimento formal sobre as práticas de ensino, a partir da problematização de seu próprio conhecimento, bem como do conhecimento e da prática de outros, assim se colocando em uma relação diferente com o próprio conhecimento. Isso porque uma única e mesma prática pode ser abordada de tantos e quantos lugares distintos possa ser vista, vivida, compartilhada e refletida.

Sendo assim, acreditamos que a formação que promove o desenvolvimento profissional docente se dá por meio da socialização das reflexões e teorias práticas dos professores. Como defendido por Zeichner (2008), as teorias são sempre produzidas por meio de práticas e as práticas sempre refletem alguma filiação teórica. É essa relação que precisa ser compreendida e aprofundada e isso precisa ser feito coletivamente.

Apostamos na ideia de reflexão de Zeicher (2008, p. 543), que a reconhece como "uma prática social que acontece em comunidades de professores que se apoiam mutuamente e em que um sustenta o crescimento do outro". A importância da reflexão conjunta, segundo o autor, é cada professor ser desafiado e, ao mesmo tempo, apoiado por meio da interação social, de modo a rever seu trabalho ou clarear aquilo em que acredita, para ganhar coragem, inclusive, para perseguir suas crenças.

\section{Percurso metodológico da pesquisa}

A formação dos professores das Salas de Leitura da DE de Piracicaba em parceria com a Universidade Pública ocorre com apoio do CNPq desde 2017. Os encontros acontecem quinzenalmente, na própria $\mathrm{DE}$, envolvendo 23 professores.

O grupo é composto por professores habilitados no curso de Magistério e licenciados em Letras, História, Teologia, Filosofia, Sociologia, Direito, Jornalismo, Matemática, Psicologia, Geografia, Educação Física, Ciências Físicas e Pedagogia. Os encontros têm a duração de 3 horas.

Para evidenciar como os professores se apropriaram das experiências de formação e (re)organizam suas concepções e práticas nas Salas de Leitura a partir do percurso 
O que se aprende e se ensina no processo de mútua formação de professores de...

compartilhado na formação, selecionamos como material de análise seis entrevistas realizadas com professoras participantes no ano de 2018, por um dos pesquisadores do grupo da pesquisa. As entrevistas aconteceram nas próprias escolas e duraram, em média, de 90 a 120 minutos cada uma. Todas elas foram audiogravadas e transcritas.

A escolha das professoras que seriam entrevistadas teve como critério que elas não atuassem no Programa Ensino Integral (PEI) ${ }^{7}$, considerando que a grande maioria das escolas estaduais ainda não estão inclusas no PEI, cujas condições de trabalho são bastante diferenciadas daquelas das escolas regulares. As entrevistas, por sua vez, tiveram o objetivo de compreender como os encontros de formação na DE têm - ou não - ajudado essas professoras no trabalho com a leitura nas Salas de Leitura.

Importante destacar que nossa intervenção assumiu um modelo de formação continuada concebida em termos coletivos e com um caráter colaborativo. Seguiu, como sistematizado por Davis et al. (2011, p. 92), uma dinâmica de interação e questionamento constante entre pares acerca das práticas pedagógicas cuja expectativa era aumentar a compreensão dos aspectos críticos envolvidos na organização do trabalho pedagógico, incentivar a experimentação didática e o uso de novas estratégias.

Buscamos constituir um grupo colaborativo considerando as características apontadas por Nacarato et al. (2008, p. 201): voluntariedade, identidade, espontaneidade e afetividade. Segundo as autoras:

A participação no grupo é voluntária, no sentido de que cada membro deseja fazer parte de um determinado grupo, com predisposição para contribuir e aprender com seus pares, a partir de um interesse comum - o que imprime ao grupo uma identidade. [...] ao mesmo tempo em que adquire uma identidade própria constituída pelos objetivos comuns, não provoca a perda dos objetivos individuais, ou seja, mantém a singularidade e a identidade de cada um de seus membros. [...] A essas características, acrescentaríamos a afetividade, ressaltada por Ferreira (2003), como elemento fundamental para a construção de um grupo de trabalho colaborativo que vai se constituindo pelas relações de respeito, negociações, trocas e contribuições entre os participantes.

Posto isto, reforçamos que é no encontro entre sujeitos que se interessaram pela pesquisa e formação que as relações vão se constituindo na linguagem e pela

7. Instituído pela Lei Complementar $n^{\circ}{ }_{1.164}$, de 4 de janeiro de 2012, alterada pela Lei Complementar $n^{\circ} 1.191$, de 28 de dezembro de 2012. 
linguagem. Nela e por ela os sujeitos se apropriam, mediados pelo outro, das múltiplas formas e possibilidades de perceber, estruturar e refletir acerca das práticas profissionais, reelaborando-as. Dessa perspectiva, a linguagem, em suas diversas formas de materialização, é o lugar de constituição dessas relações, seja no sentido da apropriação e da elaboração das práticas de significação e da compreensão dessas práticas, seja no sentido do desenvolvimento da análise e do julgamento de si mesmos.

A formação colaborativa em processo explora a dimensão interlocutiva da linguagem que emerge no contexto das discussões, aproximando-nos de uma das "características essenciais da linguagem: a reflexividade, isto é, o poder de remeter a si mesma” (GERALDI, 1997, p. 16). Essa possibilidade de a linguagem remeter a si mesma, por sua vez, aproxima os sujeitos dos próprios processos de apreensão e de elaboração das práticas, tomando suas escolhas e decisões como objeto de atenção.

A pesquisa entrelaçada ao processo de formação procurou documentar através de audiogravação os enunciados das professoras entrevistadas para posterior análise fundamentada na proposta metodológica de Bakhtin para o estudo da linguagem, que tem como princípios:

1. As formas e os tipos de interação verbal [devem ser estudados] em ligação com as condições concretas em que se realiza.

2. As formas das distintas enunciações, dos atos de fala isolados, em ligação estreita com a interação de que constituem os elementos, isto é, as categorias de atos de fala na vida e na criação ideológica que se prestam a uma determinação pela interação verbal.

3. A partir daí, exame das formas da língua na sua interpretação linguística habitual (BAKHTIN, 2002, p. 124).

A partir desses princípios, analisamos os modos como os professores se apropriam das experiências de formação e (re) organizam suas concepções e práticas nas Salas de Leitura pela mediação do curso de formação.

QUE INDÍCIOS APREENDEMOS NOS ENUNCIADOS DAS PROFESSORAS SOBRE O PROCESSO DE FORMAÇÃO E O TRABALHO COM LEITURA NAS SALAS DE LEITURA?

Discutiremos a formação de professores para o trabalho com práticas de leitura em Salas de Leitura escolares tomando para análise excertos das transcrições das 
O que se aprende e se ensina no processo de mútua formação de professores de...

entrevistas cujo objetivo foi compreender como os encontros de formação na $\mathrm{DE}$ têm - ou não - ajudado no trabalho com a leitura, em geral, e no trabalho a ser desenvolvido nas suas Salas de Leitura.

O enunciado de Vânia ${ }^{8}$ destaca a relevância do grupo colaborativo às práticas formativas:

A gente discute, tem um debate bem legal a respeito de autor, a respeito das escolas, dos colegas que fazem o trabalho lá [nas Salas de Leitura], e aí a gente tem um debate com os outros do que é melhor e do que pode ser melhorado naquilo que está tendo dificuldades. E é bem dinâmico e bem legal [...] a experiência maravilhosa que a gente tem, é essa troca de experiências, sabe? A troca de experiências um com os outros, de um falar da sua escola, de falar das experiências, que é um crescimento maior para você, né?

Retomando as ideias anteriormente desenvolvidas a partir de Cochran-Smith e Lytle (1999) acerca da concepção de conhecimento da prática, o excerto acima destaca a possibilidade de discussão e debate com os colegas que trabalham em Salas de Leitura a fim de melhorar aspectos nos quais encontram dificuldades. Tal como preconizam os autores, ao discutir e debater teorias se estuda colaborativamente, produzindo conhecimento formal sobre as práticas de ensino a partir da problematização dos conhecimentos dos próprios professores ao se encontrarem com outras e novas teorias e práticas, o que os leva a falar de experiências que produzem crescimento - e também conhecimento - maior para o grupo.

Essa vivência, na e pela linguagem, produz a troca de experiências, e essa possibilidade é um crescimento para os professores participantes do grupo. Essa prática é possibilitada pela interlocução. Ao ouvir a experiência do outro a troca acontece. Ao colocar-se no lugar do outro há o que Bakhtin (2003) denomina de compenetração, ou seja, a entrada no caminho interior do outro. A compenetração "pode me motivar para um ato ético: para a ajuda, a consolação, uma reflexão cognitiva, mas de qualquer modo [...] deve ser seguida de um retorno a mim mesmo, ao meu lugar [...], e só deste lugar o material da compenetração pode ser assimilado em termos éticos, cognitivos ou estéticos" (BAKHTIN, 2003, p. 24).

8. Todos os nomes são fictícios para resguardar a privacidade dos sujeitos. 
Tal como Vânia, Ciça desvela esse processo de entrada no caminho do outro, mas, ao mesmo tempo, de volta ao seu próprio lugar, à sua própria experiência pedagógica. Vejamos:

A minha importância, assim, é fazer com que o aluno saia daqui com gosto de conhecer histórias diferentes, autores diferentes, dizer, [...], "a minha escola, onde eu estudei, foi um lugar prazeroso, porque a professora da Sala de Leitura dava dicas de leitura, dava dicas de autores, e eu me sinto feliz por isso" [...]. Muitas vezes, [...] você senta com eles, começa a falar [...]: começa de Monteiro Lobato, uma poesia da Clarice Lispector, um poema.

Seus enunciados indiciam a transposição da troca de experiências vivida no grupo de formação para sua prática junto aos estudantes, o que se reafirma, em termos de formação, se olharmos também para o enunciado de Geni:

Nos primeiros anos [...] o que eu fiz foi mais por instinto: organizar a sala, deixar organizada, as mesas limpas, porque, se alguém precisasse eu estaria ali. [...]Aí, eu comecei com o que a gente aprendeu um pouquinho com a [formadora e pesquisadora], a separar por gênero: Infanto-juvenil, Romance, Contos, Crônicas... Então ficou mais fácil para a gente estar atuando, indicando para os alunos.

Tanto o enunciado de Ciça a respeito de Monteiro Lobato, Clarice Lispector e poemas, quanto o enunciado de Geni sobre romance, contos, crônica, referem-se menos à questão da organização da sala e mais ao trabalho pedagógico com a leitura, objetivo da formação. Ambas evidenciam o modo como se apropriaram dos conceitos discutidos dando relevância à mediação pedagógica a partir de uma concepção de leitura que trabalha com diferentes gêneros discursivos9.

A Resolução SE 70/2011 (SÃO PAULO, 2011) destaca a importância da organização e controle do acervo e das instalações das salas e esse discurso circula nas escolas. Os professores são cobrados para a realização dessa prática organizativa, mas ao enunciar que a gente aprendeu [...] a separar por gênero [.... Então, ficou, também, mais fácil para a gente estar atuando, indicando para os alunos (sic), Geni faz o deslocamento dos cuidados organizativos para o trabalho efetivamente pedagógico.

9. Segundo Bakhtin (2003), os gêneros do discurso são tipos relativamente estáveis de enunciados que se produzem e se estabilizam nas condições específicas e nas finalidades das diferentes esferas de utilização da língua. 
O que se aprende e se ensina no processo de mútua formação de professores de...

Se, anteriormente, Ciça e Geni explicitaram o deslocamento do lugar de apenas organizadoras da sala para o lugar de mediadoras do trabalho pedagógico com leitura, objetivo da formação, Helena explicita-nos a potência de argumentação que a formação lhe propiciou: "Muito pela troca de experiência [...] pelas pessoas estarem falando o que fazem [...] Então, essa troca fortalece, porque senão eu já teria desanimado, $[. .$.$] pediram para eu ficar na secretaria [. .$.$] se eu não estivesse$ na formação me fortalecendo, eu estaria cedendo".

Esse excerto materializa as proposições de Davis et al. (2011) acerca da dinâmica de interação e questionamentos constantes entre os pares do grupo colaborativo de formação, uma vez que a rica discussão tanto sobre os fatores da profissão docente quanto sobre o papel do professor da Sala de Leitura aumentou a consciência crítica de Helena, ou seja, se eu não estivesse na formação me fortalecendo, eu estaria cedendo e isso significa o compromisso da formação com mudanças necessárias nas escolas em prol da formação de alunos leitores na escola de educação básica.

Ainda sobre o enunciado de Geni, é relevante destacar o modo como ela explicita a proposição de leituras aos alunos. Relembremos: a gente aprendeu [...] a separar por gênero: Infanto-juvenil, Romance, Contos, Crônicas. A professora não só destaca os gêneros do discurso, mas os gêneros literários. Como afirma Petit (2009, p. 113), a literatura é capaz de transformar o inenarrável em narrável modificando o homem. Essa potência da leitura literária tem sido um eixo condutor das discussões no contexto da formação. Isso porque entendemos, com Lacerda (2007), que a leitura da literatura é um processo estético e tem como característica fundamental o investimento na perplexidade do ser humano frente à vida; esse tem sido um princípio de nossa formação.

Outros enunciados destacam a importância dos aprendizados no contexto da formação sobre como poderiam agir junto aos colegas, no contexto escolar, para estabelecimento de parcerias e aceitação do trabalho que realizam.

Este ano [2018], eu [...] no planejamento [...] me apresentei, falei alto para todo mundo e falei para visitarem a sala de leitura, que eu estava à disposição e que poderiam entrar [...], sentar com os alunos, fazer trabalho, indicar livros, que eu estaria ajudando. Então, os professores, principalmente de Português, ficaram super animados, e outros também [...] então começaram a me procurar. Aí eu percebi que, realmente, você tem que estar atrás deles também, conversando com eles... A dica das meninas da formação é: tenha amizade com os professores de português, principalmente (Lila). 
Não tem problema, porque eu faço meu esquema, como digo eu, daí eu vou comendo pelas beiradas e vou falando, e comendo pelas beiradas você consegue: quando os professores menos esperam, já estão na Sala de Leitura e já estão fazendo. Na formação aprendemos assim, tem que ir comendo pelas beiradas, e eu vou (Helena).

Se a constituição de nossa pessoalidade acontece no encontro com o outro, a constituição de nossa profissionalidade não poderia ser diferente. Para além das discussões no grupo de formação, e a partir de dicas recebidas no contexto do grupo, Lila se apresenta, convida os outros professores da escola a frequentarem a Sala de Leitura.

Pessoalidade e profissionalidade não acontecem de forma dissociada, uma vez que a formação de professores não acontece apenas em espaços e instâncias formais - como nos encontros da $\mathrm{DE}$, por exemplo -, mas também pela mediação de práticas relacionais e experienciais - tais como na escola e no contexto da prática profissional -, as quais mobilizam trocas de conhecimentos entre os professores, e esse processo de formação constitui-se na interlocução/interação (BAKHTIN, 2002), ou seja, pessoalidade e profissionalidade se constituem como processos de produção de sentidos, instaurados, materializados, constituídos e mediados pela linguagem.

A linguagem, nesse sentido, não só é constitutiva do humano mas é o lugar da interação, pois é na (inter/oper)ação, na relação com o outro no movimento de significação e produção de sentidos, "que ela [linguagem] funciona, às vezes, por si, produzindo múltiplos efeitos, [...] e sentidos se produzem com/por ela, nela e 'fora' (ou além) dela" (SMOLKA, 1993, p. 19-20). Essa proposição nos ajuda a conduzir e compreender tanto a prática da formação quanto a atividade de leitura como um processo de constituição sócio-histórica e de produção de sentidos, o que acontece na diversidade dos contextos de sua produção.

Helena, por sua vez, destaca os embates no miúdo da escola, no cotidiano diário. Segundo ela, parece-nos, a expressão "comer pelas beiradas" indicia a aproximação junto aos professores, uma argumentação supostamente despretensiosa, o que os aproxima da Sala de Leitura para uma parceria de trabalho.

Segundo Faria Filho (2005), embora tenhamos um grande número de estudos sobre os processos de escolarização e, diríamos aqui, sobre a formação docente, no mais das vezes naturalizamos a escola e o que nela acontece e pouco indagamos acerca dos processos cognitivos priorizados e das estratégias e recursos utilizados de maneira a mediar a produção e a circulação do conhecimento dentro dela. No entanto, os enunciados de Lila e Helena, ao nosso ver, contribuem para a explicitação tanto das 
O que se aprende e se ensina no processo de mútua formação de professores de...

contradições que se presentificam na prática efetiva vivida nas escolas e nas Salas de Leitura, quanto das possibilidades de exploração dessas contradições em favor de "um espaço de atuação profissional em que se delineie um fazer agora, na escola que temos, alguma coisa que nos aproxime da escola que queremos e que dependem de determinantes externos aos limites da ação da e na própria escola” (GERALDI, 1997, p. 40).

$\mathrm{O}$ modo de fazer compartilhado, em parceria com os outros professores da escola, no cotidiano da sala de leitura, vai sendo explicitado no processo de formação. Vejamos o que Salma nos diz:

Esse ano já estou com uma parceria com a professora de português, um professor de história e outro professor de português. A gente vai fazer um trabalho com eles para, como a formadora diz, cotejar os textos: o texto que ele está trabalhando sobre a mineração, eu vou indicar uma literatura sobre a mineração. A gente [...] vai trabalhar com o professor de história, com os sextos anos. [...] uma literatura bem infanto-juvenil, bem para a idade deles. E, com os oitavos, vou trabalhar com A Revolução dos Bichos. A gente vai tentar fazer uma discussão com o professor de história e o professor de português: trabalhar a narrativa com o professor de português, e as questões políticas com os professores de História e Geografia, como aprendemos aqui na formação.

Ao chamar a atenção para esse ano já estou com uma parceria, Salma explicita uma prática decorrente de um processo de negociação com os professores, tal como indiciado anteriormente tanto por Lila quanto por Helena. Inscrita tanto nas relações da formação, expressa pelo enunciado como a formadora diz, quanto nas relações de ensino, pelo enunciado já estou com uma parceria, Salma e seus colegas professores alteraram relações na escola e trabalharão juntos em prol da formação de alunos leitores. Ainda, Salma chama a atenção para o trabalho da e com a leitura literária, tal como abordado anteriormente, um princípio fundante do nosso processo de formação.

\section{Aprendizados do/no PRoCesso de mútua formaÇão}

Entendemos que o processo de formação, bem como de reflexões e (re)organização de concepções e práticas pedagógicas vividas nas Salas de Leitura, só podem ser entendidos como mútua formação se forem analisados a partir de uma concepção essencialmente dialógica. Na perspectiva assumida não há outra forma viável para a 
condução e mediação de processos tão subjetivos quanto os das aprendizagens que se (re)constroem a todo momento na constituição pessoal e profissional dos sujeitos. Fazer a escolha por essa perspectiva é estar em eterna construção do conhecimento.

Em tempos como os atuais, em que o trabalho de formação que valoriza a prática docente é política e socialmente desvalorizado, parece-nos eticamente necessário valorizar as práticas que tentam se desviar de uma realidade de faltas - falta de materiais, falta de parcerias, falta de formação, tudo falta... Ao contrário, pela interação e interlocução nas atividades de formação de e para leitura os professores se aproximaram de outros olhares não só para as práticas pedagógicas vividas nas Salas de Leitura, mas também nos modos de se relacionarem com os colegas no cotidiano escolar, a favor da leitura. Garantindo olhar para os outros que os cercam - alunos e colegas professores e construindo as práticas escolares, procuraram transformar o movimento de reflexão vivido no contexto da formação e da pesquisa, mesmo que não de maneira formal, em movimento de reflexão vivido nas práticas e alternativas do contexto escolar.

Os relatos expressos acerca das práticas vividas nas escolas parecem ter servido para intensificar a importância do processo de formação, reafirmando a não dicotomia entre formação pessoal e profissional. Por ser um movimento dialógico, a palavra do outro perpassa discursos e ações atravessando o outro que está dentro de nós. Alterando os lugares de fala - professores em formação/professores em atuação nas escolas - reflexões foram sendo tecidas pelo processo de formação com e para a leitura, em um trabalho de consolidação do diálogo e da parceria no trabalho pedagógico vivido no contexto das escolas.

\section{REFERÊNCIAS}

BAKHTIN, M. Estética da criação verbal. Tradução de Paulo Bezerra. 4. ed. São Paulo: Martins Fontes, 2003.

BAKHTIN, M. Marxismo e filosofia da linguagem. São Paulo: Hucitec, 2002.

BAPTISTA, K. C. A constituição de si e do outro: a experiência formativa de professores de sala de leitura. 2018. Dissertação (Mestrado em Educação) - Faculdade de Educação, Universidade Estadual de Campinas, Campinas, 2018.

COCHRAN-SMITH, M.; LYTLE, S. L. Relationships of knowledge and practice: teacher learning in communities. Review of Research in Education, USA, n. 24, p. 249-305, 1999.

COCHRAN-SMITH, M.; LYTLE, S. L. Inquiry as stance: ways forward. In: COCHRAN-SMITH, M.; LYTLE, S. L. Inquiry as stance: practitioner research for the next generation. New York: Teachers College Press, 2009. p. 118-165. 
O que se aprende e se ensina no processo de mútua formação de professores de...

CUNHA, M. I. O tema da formação de professores: trajetórias e tendências do campo na pesquisa e na ação. Educação e Pesquisa, São Paulo, v. 39, n. 3, p. 609-625, jul./set. 2013. Disponível em: http:// www.scielo.br/pdf/ep/2013nahead/aop1096.pdf. Acesso em: 3 out. 2019.

DAVIS, C. et al. Formação continuada de professores: uma análise das modalidades e das práticas em estados e municípios brasileiros. Estudos e Pesquisas Educacionais, São Paulo, v. 41, n. 144, p. 826-849, set./dez. 2011, p. 81-166. Disponível em: http://www.scielo.br/pdf/cp/v41n144/ v41n144a1o.pdf. Acesso em: 3 out. 2019.

DINIZ-PEREIRA, J. E. A pesquisa dos educadores como estratégia para construção e modelos críticos de formação docente. In: DINIZ-PEREIRA, J. E.; ZEICHNER, K. M. (Org.). A pesquisa na formação e no trabalho docente. 2. ed. Belo Horizonte: Autêntica, 2011. p. 11-38.

FARIA FILHO, L. M. (Org.) Pensadores Sociais e História da Educação. Belo Horizonte: Autêntica, 2005.

GERALDI, J. W. (Org.). O Texto na Sala de Aula. São Paulo: Ática, 1997.

LACERDA, N. G. Para atravessar o território desconhecido, a caminho do amanhã. In: Debate: Temas polêmicos na literatura. Programa Salto para o Futuro, TVE Brasil. Boletim n. 11, Programa 5, junho de 2007.

NACARATO, A. M. et al. Professores e futuros professores compartilhando aprendizagens: dimensões colaborativas em processo de formação. In: PAIVA, M. A. V. A formação do professor que ensina matemática: perspectivas e pesquisas. Belo Horizonte: Autêntica, 2008. p. 197-212.

PETIT, M. A arte de ler: ou como resistir à adversidade. Tradução de Arthur Bueno e Camila Boldrini. São Paulo: 34, 2009.

SÃO PAULO (Estado). Resolução SE - 15, de 18 de fevereiro de 2009. Dispõe sobre a criação e organização de Salas de Leitura nas escolas da rede estadual de ensino. Diário Oficial do Estado de São Paulo, São Paulo, v. 118, n. 34, p. 39, 19 fev. 2009. Seção1.

SÃO PAULO (Estado). Resolução SE - 70, de 21 de outubro de 2011. Dispõe sobre a instalação de Salas e Ambientes de Leitura nas escolas da rede pública estadual. Diário Oficial do Estado de São Paulo, São Paulo, 22 out. 2011. Seção1, p. 16.

SMOLKA, A. L. B. A criança na fase inicial da escrita - A alfabetização como processo discursivo. 5. ed. Campinas: Editora da Universidade Estadual de Campinas; São Paulo: Cortez, 1993.

TARDIF, M. Saberes profissionais dos professores e conhecimentos universitários. Elementos para uma epistemologia da prática profissional dos professores e suas consequências em relação à formação para o magistério. Revista Brasileira de Educação, Rio de Janeiro, n. 13, p. 5-24, jan./ abr. 200o. Disponível em: http://anped.tempsite.ws/novo_portal/rbe/rbedigital/RBDE13/ RBDE13_05_MAURICE_TARDIF.pdf. Acesso em: 3 out. 2019.

ZEICHNER, K. M. Uma análise crítica sobre a "reflexão" como conceito estruturante na formação docente. Educação e Sociedade, Campinas, v. 29, n. 103, p. 535-554, maio/ago. 2008. Disponível em: http://www.scielo.br/pdf/es/v29n103/12.pdf. Acesso em: 3 out. 2019.

ZEICHNER, K. M. Para além da divisão entre professor-pesquisador e pesquisador acadêmico. In: GERALDI, C. M.; FIORENTINI, D.; PEREIRA, E. M. (Org.). Cartografia do trabalho docente: professor(a)-pesquisador(a). Campinas, SP: Mercado de Letras; ABL, 1998. p. 207-236. 
SOBRE AS AUTORAS

Cláudia Beatriz de Castro Nascimento Ometto é graduada em Pedagogia (Universidade Metodista de Piracicaba), tem Mestrado em Educação (Universidade Metodista de Piracicaba) e Doutorado em Educação (Universidade Estadual de Campinas). É professora/pesquisadora da Universidade Estadual de Campinas. Tem experiência na área de Educação com pesquisa nos seguintes temas: leitura, escrita, alfabetização, salas de leitura, formação de professores, práticas de ensino.

E-mail: cbometto@yahoo.com.br.

Renata Cristina Oliveira Barrichelo Cunha é graduada em Pedagogia (Pontifícia Universidade Católica de São Paulo) e Doutorado em Educação (Universidade Estadual de Campinas). É professora/pesquisadora do Centro Universitário Salesiano de São Paulo. Tem experiência na área de Educação, com pesquisa nos seguintes temas: formação de professores, trabalho docente coletivo, coordenação pedagógica, cotidiano escolar, relação universidade-escola e relação escola-comunidade.

E-mail: renata_bcunha@yahoo.com.br.

Recebido em 11 de outubro de 2019 e aprovado em 05 de fevereiro de 2020. 